\section{Reply to Tognù et al: regional anesthesia for proximal humerus surgery during COVID-19 pandemic}

\section{To the Editor}

We read the letter entitled 'Proximal humeral fracture surgery in the COVID-19 pandemic: advocacy for regional anesthesia' with great interest. ${ }^{1}$ We agree with the authors on using regional anesthesia (RA) in trauma patients whenever applicable during this pandemic. However, it should also be considered that an sion to general anesthesia (GA) is least desirable in patients with COVID-19. ${ }^{2}$

The application of RA for surgical anesthesia needs thorough understanding of the dermatome, myotome and osteotome of the surgical field. The authors proposed a combination of ultrasound-guided interscalene block (ISB) and supraclavicular brachial plexus block (SCB) for proximal humeral surgeries as stand-alone RA technique. Falyar et al used this combination for intramedullary nailing of a pathologic humeral fracture. ${ }^{3}$ We have been using this combination for surgeries involving proximal and shaft of humerus with good surgical anesthesia and patient satisfaction. To be precise, we use combination of upper trunk block and subclavian perivascular brachial plexus block. However, unplanned need for intraoperative conver- these combinations are always not enough to cover the surgical incision.

A detailed knowledge of innervations around shoulder is important to choose appropriate RA technique, prevent failure and avoid conversion to GA. Axillary nerve (C5-C6) and suprascapular nerve (C5-C6) supply major part of the osteotome and myotome around the shoulder and proximal humerus. Subscapular (C5-C6), medial pectoral (C8-T1), lateral pectoral (C5-C7), musculocutaneous (C5$\mathrm{C} 7)$, thoracodorsal (C6-C8) and radial nerves (C5-T1) also contribute to supply myotomes. The dermatome is supplied by axillary, supraclavicular (C3-C4), anterior cutaneous branches of intercostal nerves (T2-T4) and radial nerve. ISB typically covers only C5-C6. Combining SCB with ISB results in anesthesia and analgesia of C5-T1 dermatomes. Additional subcutaneous local anesthetic (LA) infiltration along the incision line or superficial cervical plexus block and/or intercostobrachial nerve block may be required depending upon the type of surgery and site of incision.

Ultrasound-guided low volume ISB or upper trunk block helps to decrease incidence of phrenic nerve palsy and other complications which are particularly important in patients with compromised lung function. ${ }^{4}$ Combining low volume ISB and SCB can still increase the possibility of transient phrenic nerve palsy due to increase cumulative LA volume. Alternative approaches like combined infraclavicular brachial plexus block with suprascapular nerve block can be tried in high-risk patients. ${ }^{5}$ LA systemic toxicity (LAST) is another concern whenever we use multiple blocks. Appropriate measures must be taken as per the recommendations to preventLAST during covid-19 pandemic.

\section{Tuhin Mistry ${ }^{\circ},{ }^{1}$ Elayavendhan Kuppusamy ${ }^{2}$ \\ ${ }^{1}$ Department of Anaesthesiology, All India Institute of Medical Sciences, Raipur, Chhattisgarh, India ${ }^{2}$ Department of Anaesthesiology, Ganga Medical Centre and Hospitals Pvt Ltd, Coimbatore, Tamil Nadu, India}

Correspondence to Dr Tuhin Mistry, Anaesthesiology, All India Institute of Medical Sciences, Raipur 492099, Chhattisgarh, India; tm. tuhin87@gmail.com

Acknowledgements The authors acknowledge Dr. Ankita Chaki for her support in editing of the manuscript.

Contributors All authors contributed equally to the manuscript.

Funding The authors have not declared a specific grant for this research from any funding agency in the public, commercial or not-for-profit sectors.

Competing interests None declared.

Patient consent for publication Not required.
Provenance and peer review Not commissioned; internally peer reviewed.

This article is made freely available for use in accordance with BMJ's website terms and conditions for the duration of the covid-19 pandemic or until otherwise determined by BMJ. You may use, download and print the article for any lawful, non-commercial purpose (including text and data mining) provided that all copyright notices and trade marks are retained.

C American Society of Regional Anesthesia \& Pain Medicine 2021. No commercial re-use. See rights and permissions. Published by BMJ.

\section{Check for updates}

To cite Mistry T, Kuppusamy E. Reg Anesth Pain Med 2021;46:376.

Received 22 May 2020

Accepted 23 May 2020

Published Online First 2 June 2020

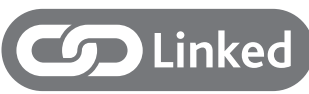

- http://dx.doi.org/10.1136/rapm-2020-101626

Reg Anesth Pain Med 2021;46:376.

doi:10.1136/rapm-2020-101729

\section{ORCID iD}

Tuhin Mistry http://orcid.org/0000-0003-1904-4831

\section{REFERENCES}

1 Tognù A, Barbara E, Pacini I. Proximal humeral fracture surgery in the COVID-19 pandemic: advocacy for regional anesthesia. Reg Anesth Pain Med 2021;46:376-7.

2 Uppal V, Sondekoppam RV, Lobo CA, et al. Practice recommendations on neuraxial anesthesia and peripheral nerve blocks during the COVID-19 Pandemic- a joint statement by the American Society of regional anesthesia and pain medicine (ASRA) and European Society of regional anesthesia and pain therapy (ESRA), 2020. Available: https:/ www.asra.com/content/documents/ra-covid19_final.pdf

3 Falyar CR, Grossman EC. Ultrasound-Guided interscalenesupraclavicular block for an intramedullary nailing of a pathologic humeral fracture: practical application of ultrasound-guided regional anesthesia. Aana J 2014;82:219-22.

4 Riazi S, Carmichael N, Awad I, et al. Effect of local anaesthetic volume (20 vs $5 \mathrm{ML}$ ) on the efficacy and respiratory consequences of ultrasound-guided interscalene brachial plexus block. Br J Anaesth 2008;101:549-56.

5 Tran DQH, Elgueta MF, Aliste J, et al. Diaphragm-Sparing nerve blocks for shoulder surgery. Reg Anesth Pain Med 2017;42:32-8. 